\title{
EL ESTADO EN AMÉRICA LATINA DESDE LA INDEPENDENCIA
}

\author{
Alan Knight*
}

\begin{abstract}
Resumen
Este artículo trata sobre el Estado latinoamericano, su carácter y evolución histórica. La primera parte ofrece enfoques teóricos y conceptuales que pueden ayudarnos en el análisis del Estado; la segunda parte describe la trayectoria del Estado en América Latina, utilizando una periodización que abarca desde la Independencia hasta el presente.
\end{abstract}

Palabras clave: Estado, construcción de Estado, nación, nacionalismo, populismo, liberalismo, neoliberalismo

\section{The state in Latin America since Independence}

\begin{abstract}
This paper discusses the Latinamerican state, its nature and historical evolution. The first part provides theorical and conceptual approaches that help us when analysing the state; the second part describes the trajectory of the state in Latin America, using chronological frameworks from Independence until today.
\end{abstract}

Keywords: State, state-building, nation, nationalism, populism, liberalism, neoliberalism 
$\mathrm{E}$ $\mathrm{n}$ años recientes se han publicado libros exhortándonos a 'reintroducir al Estado' o 'reinvindicar lo político' -exhortaciones un poco exageradas, ya que el Estado nunca ha sido omitido (Evans I985). El Estado nos suministra la mayoría de nuestros archivos y, si una escuela de ciencia política (principalmente norteamericana) suele descartar al Estado como actor autónomo, nosotros los latinoamericanistas, trabajando otro campo con otras perspectivas, rara vez lo hacemos. De hecho, hemos enfatizado el papel del Estado (en México se habla de la 'estadolatría'), igual que la llamada tradición centralista de Véliz (1980), y la mano muerta del dirigismo económico (Landes I998: Cap. 20).

Para armar el análisis comienzo con una discusión conceptual del Estado (ilustrada con ejemplos concretos), para después ofrecer una periodización histórica. Los politólogos, entonces, deben prestar su atención a la primera parte; los historiadores a la segunda.

\section{El concepto del Estado}

Para entender el concepto del Estado, creo que se deben realizar tres tareas: definirlo; tratar la cuestión de la legitimidad; y considerar sus funciones, es decir, definir qué hace el Estado.

Primero, vale distinguir entre Estado y nación. Los Estados latinoamericanos decimonónicos fueron 'Estados-nación', conforme la idea entonces dominante de que toda nación mereció 'su' Estado y todo Estado estaba basado en una nación; una idea algo utópica, ya que los Estados establecidos de Europa (Inglaterra, Francia, España, Rusia) fueron mezclas étnicas, mientras que Italia y Alemania no exis- 
tieron como naciones o Estados hasta la segunda mitad del siglo XIX. Los países latinoamericanos también fueron étnicamente diversos, de tal manera que varios historiadores han dudado si acaso alguna vez constituyeron naciones. Sin embargo, queda claro que existieron Estados -aunque fueran débiles-que hicieron lo que estos suelen hacer (cobrar impuestos, hacer leyes, luchar guerras), al tiempo que demandaron soberanía sobre territorios que ya no formaban parte de imperios dinásticos transatlánticos y que gobernaban conforme el supuesto 'interés nacional' (no el interés dinástico o religioso). Por supuesto, los Estados (de entonces y después) promovieron el nacionalismo porque, si lo hacían existosamente, aumentaban sus recursos discursivos. En un Estado-nación consolidado (y, no obstante la situación en el siglo XIX, queda claro que tales Estados sí existieron en la América Latina del XX) el Estado fácilmente puede confundir 'forjar-nación' con el 'forjar-Estado' (cosa que se ve en la obra del antropólogo mexicano Manuel Gamio, autor del libro Forjando Patria [I9I6], entre muchos otros). Pero esta perspectiva -que prefigura la interpretación 'modernista' e 'instrumentalista' del nacionalismo, desplegada por Hobsbawm (I992) y Gellner (I983)- no debe ser ciegamente aceptada. Más bien, como historiadores, debemos considerar cuestiones pendientes acerca de la relación Estado-nación: por ejemplo, ¿‘uál ocurre primero?; ¿emergieron los Estados del agonizante imperio español -algo al azar-, para después construir las naciones 'de arriba hacia abajo' (conforme la tesis modernista)?; o, más bien, ¿existeron 'proto-naciones' debajo de la caparazón imperial, que alcanzaron su libertad con la Independencia (conforme la tesis 'primordial')? No abundaré en el tema, aunque creo que en el caso de México, que conozco, y quizás el de Chile (donde me confío en el trabajo de Simon Collier I967), sí hay evidencia de sentimientos 'proto-patrióticos' que explican, al menos en parte, la caída del imperio y la formación de las nuevas naciones hispanoamericanas. Por lo tanto, estos no fueron territorios enteramente contingentes, sin sentido de sí mismos (Brading I99I: Caps. I4 y 20 ).

Más allá de este debate, queda claro que Estado y nación, mezclados en la práctica, son analíticamente distintos. Ha habido muchos Estados sin base nacional (imperios, Estados-ciudad), y naciones po- 
tenciales sin Estado (los Kurdos y Catalanes, quizás los maya, aymara, quechua y mapuche). ${ }^{\mathrm{I}}$ Las posibles combinaciones de Estados fuertes o débiles, con naciones fuertes o débiles, son múltiples y relevantes en la historia latinoamericana.

El Estado, entonces, invoca soberanía sobre un territorio ('nacional') donde, conforme la tesis de Max Weber (I964: I56), trata de ejercer un monopolio de la coerción legítima, una definición que incluye dos elementos: un monopolio (que no tolera rivales) de la coerción legítima (por tanto una dictatura ilegítima no cuadra con la definición weberiana -a lo cual volveré).

Al desplegar su poder, el Estado tiene facultades diagnósticas, sin las cuales deja de funcionar: fuerzas coercitivas, burocracia, una capital, una moneda legal, una Constitución y leyes. Estas facultades sobreviven aún cuando existan cambios de gobierno o -más importante- de régimen. Por ejemplo, hay continuidades en el Estado chileno a través de las luchas civiles y los golpes de los años I925 y I973. La durabilidad sugiere cierta legitimidad: una amplia aceptación del Estado como fuente de autoridad, que más vale obedecer, y no simplemente debido a la coacción. ${ }^{2}$ Hay casos -extraños- cuando el Estado (no simplemente el gobierno o el régimen) deja de existir. Por ejemplo, en México en I9I4, cuando el antiguo régimen se derrumbó, la moneda colapsó y diversas facciones lucharon por el poder. Pero, no obstante el estereotipo, América Latina ha vivido pocas experiencias de esta índole. Un fenómeno más frecuente ha sido la implosión del Estado, su ahuecamiento interior por fuerzas ya sea regionales (los caudillos del norte de México o del noroeste de la Argentina), o criminales (los carteles de Sinaloa o Medellín), o revolucionarias (las Fuerzas Armadas Revolucionarias de Colombia o Sendero Luminoso). Claramente tales conflictos niegan al Estado su estatus weberiano. Sin embargo, los Estados son entes tenaces que, después de estos episodios, suelen recuperarse y, de hecho, durante el período bajo consideración, la tendencia ha sido su fortalecimiento, no su debilitamiento.

\footnotetext{
${ }^{\mathrm{I}}$ Estos son casos bien conocidos; Woodard (20II) ofrece una tesis semejante (pero menos convincente) en cuanto a los Estados Unidos.

${ }^{2}$ Un antiguo aspecto -incluso un antiguo enigma- del Estado, como reconoció David Hume hace 270 años: "para los que consideran los asuntos humanos con ojos filosóficos, nada parece más sorprendente que la facilidad con la cual los muchos son gobernados por los pocos; y la sumisión implícita con que los hombres confían [resign] sus sentimientos y pasiones a los de sus gobernantes" (Hume I963: 29).
} 
Mucho más frecuentes han sido los cambios de gobierno/administración o de régimen (por régimen, quiero decir la forma del Estado, ya sea oligárquica, democrática, militar, revolucionaria, etc.). La legitimidad puede ser un rasgo del Estado o del régimen. Las súbitas caídas de los régimenes de Porfirio Díaz en México (I9II) y de Gerardo Machado en Cuba (I933) fueron clara evidencia de su falta de legitimidad, y además provocaron revoluciones populares. Los golpes y cuartelazos son evidencias mucho más débiles, ya que -en la Argentina en I930, por ejemplo- los golpistas fueron una pequeña minoría. ${ }^{3}$ Aun cuando es imposible medir la legitimidad (incluso las encuestas no son tan fiables en este sentido), creo que es un concepto esencial para entender la función de los Estados y los regímenes (no tanto de las administraciones). Generalmente, la discusión del tema se enfoca simplemente en el propio Estado (o régimen), pero en la realidad este enfoque es demasiado estrecho. La legitimidad involucra exigir la obediencia de los ciudadanos y, mientras haya situaciones -como la defensa del territorio nacional- en que el Estado es el actor principal, quizás único, hay muchas otras en donde el Estado se enfrenta a otras autoridades, otros actores colectivos, que también exigen obedencia y ostentan una suerte de legitimidad propia. Algunos, ya mencionados (caudillos, carteles y movimientos revolucionarios), son dotados de poder coercitivo, pero también tienen sus recursos discursivos, materiales y clientelísticos (al estilo del propio Estado). Los caudillos dependen de intereses e identidades regionales; los movimientos revolucionarios de agravios históricos y promesas para el futuro; los carteles ofrecen puestos, sueldos, prestigio y movilidad social -además de premios psicológicos, gracias al culto macho del narco, con sus corridos, videos, coches, y cuernos de chiva (Knight I998: 47).

Por añadidura, hay actores colectivos que pueden enfrentarse al Estado sin utilizar un machete o un cuerno de chiva. ¿Cuántos batallones tiene el Papa, preguntó Stalin? Pocos o ninguno. Pero la Iglesia Católica fue una fuerza poderosa y un contrincante serio; por lo tanto, la legitimidad del Estado fue en parte una función de la contra-legitimidad de la Iglesia y de la relación Estado-Iglesia. Había gobiernos -como Rafael Carrera en Guatemala y Gabriel García Moreno en Ecuador- que emularon

\footnotetext{
${ }^{3}$ David Rock describe cómo el golpe de I930 "fue llevado a cabo con poca preparación y pocas fuerzas" (I987: 215).
} 
la alianza de trono y altar del antiguo régimen europeo; una alianza que limitó la libertad del Estado (en cuanto a la desamortización, la educación, la reforma judicial), pero que afianzó la estabilidad política (siendo una prueba negativa los recurrentes conflictos provocados por políticas anticlericales en México y Colombia). De la misma manera, en el siglo XX gobiernos argentinos -como los de Yrigoyen y de los Radicales- mantuvieron buenas relaciones con la Iglesia, igual como lo hicieron las juntas militares de los años sesenta y setenta. Perón comenzó así, y fue su lucha con la Iglesia en I954 lo que presagió su caída. Incluso Fidel Castro, inicialmente anticlerical, excomulgado en I962, después fraguó un arreglo con la Iglesia, cuestión que Lázaro Cárdenas también hizo treinta años antes. Castro y Cárdenas fueron radicales que se enfrentaron a una Iglesia conservadora, pre-Medellín; en Brasil, el régimen militar fue opuesto y debilitado por una Iglesia más progresista y popular.

La Iglesia es el rival (potencial) más antiguo y fuerte del Estado. Otros menores han venido y se han ido. A principios del siglo XX el anarquismo puso un reto radical al Estado, especialmente en el Cono Sur. Empero, con la Revolución Rusa y, más importante, con el desarrollo de los Estados reformistas e inclusivos, el movimiento obrero se volvió más moderado, socialista y dispuesto a fraguar alianzas con el Estado: con la Confederación Regional Obrera Mexicana, con Perón en Argentina y (en cierta medida) con Vargas en Brasil. Así, el acercamiento Estado-Iglesia tuvo una contraparte en la 'incorporación' obrera por parte del Estado, conforme el análisis de Berins Collier y Collier (I992). Por supuesto, no se trata de un proceso lineal. Mientras que el conflicto religioso (Estado-Iglesia) ha disminuido -gracias en parte al crecimiento del protestantismo evangélico, siempre más deferencial frente a la autoridad secular, y a la declinación tanto del integrismo católico como de la teología de la liberación-, el reto del radicalismo (socialista, comunista) ha sido más cíclico. El anarquismo vino y se fue; la Revolución Cubana provocó emulación en otros países (sin mucho éxito); y Sendero armó un reto existencial al Estado peruano que, al final, se esfumó. Actualmente, la contestación política radical y popular parece en retirada, lo que favorece la estabilidad del Estado. Si esta situación es permanente $\mathfrak{u}$, otra vez, cíclica, lo mencionaré hacia el final.

El tercer y último punto conceptual tiene que ver con la función del Estado, referida a su relación con la sociedad civil, que determina 
en gran parte el nivel de legitimidad. No faltan teorías del Estado, que se remontan a Platón o antes. Muchas son normativas: nos dicen cómo debe comportarse el Estado (al estilo del propio Platón). Obviamente, las normas del Estado -su 'guión público', en palabras del antropólogo James Scott (I990: 2SS)- son importantes y merecen investigación. Pero el historiador no debe preocuparse por la ética del Estado; tampoco debe proyectar sus propias preferencias normativas (si, al final de este artículo los lectores no tuvieran la menor idea de mis preferencias político-normativas, tanto mejor). Conforme a la distinción que Hume hizo entre is y ought (lo que es y lo que debe ser), el historiador se interesa en is o, mejor dicho, was, lo que pasó, y por qué (I739: Libro III, Parte I, Sección i).

Resumiendo las teorías del Estado, podemos dividirlas en dos (aunque la segunda tiene varias subcategorías). La primera, más fuerte en EE. UU., ve al Estado como una arena neutral donde los individuos y los intereses compiten; el Estado -a veces lo denominan el Estado 'vigilante' [nightwatchman]- mantiene las reglas del juego; es un árbitro, no un jugador (de ahí el llamamiento para 'reintroducir el estado' que mencioné al principio).

En América Latina -quizás en todo el mundo- el Estado 'vigilante', aún más que el clásico Estado weberiano, es un mito, una distorsión de la realidad histórica. La mayoría de los Estados no se han limitado al papel de árbitro; han escrito las reglas y han bajado a la arena para participar en el juego, o en la contienda gladiatoria. Pero ¿cuáles son esas reglas? Una versión, que no me convence como hipótesis empírica, es el modelo tomista, de un Estado que tiene una relación paternal y orgánica con una sociedad corporativa (bien descrito por Alfred Stepan (I978: 4, 26-45) en su estudio de la política peruana). Como discurso normativo (o 'guión público'), al estilo de Scott (I990), el modelo tomista-corporativo puede ser interesante; pero como modelo explicativo de la actuación del Estado en la historia, no me convence.

Un segundo enfoque es el clásico modelo marxista del Estado como 'comité ejecutivo de la clase dominante' (Miliband I973: 7). Muy influyente en el análisis latinoamericano, también tiene sus problemas. Primero, presume que existe una 'clase dominante' homogénea, con sus intereses definidos, cuando sabemos que en América Latina esa clase ostentó diferencias sectoriales, regionales e ideológicas. Segundo -y aquí 
reciclamos el antiguo debate 'Miliband-Poulantzas' de los setenta ${ }^{4}-$ vale preguntarse si la clase dominante ocupa directamente al Estado o, más bien, confía en agentes políticos suyos. Los opulentos estancieros argentinos de fines del siglo XIX desdeñaron los puestos políticos, dejándolos en manos de caciques (mejor dicho, de caudillos) partidistas, de origen social inferior; en igi6 la élite económica toleró la democratización en parte porque la vieron como una manera de frenar a estos -ya demasiado autónomos- caciques (Hora 200I). En contraste, los terratenientes menores del noroeste -en Salta y Jujuy-ocuparon los puestos políticos, para así proteger sus intereses económicos y su control coercitivo de la mano de obra (Rutledge i977: Cap. 8). Pero el patrón del litoral -una división de trabajo entre élites económicas y una clase política 'especialista'- se ve en muchos casos: con el PRI en México (donde la creciente burguesía coexistió con el partido oficial); o en el Cono Sur, donde la burguesía -a veces- concedió el poder político a los militares, aun si al final tuvo que lamentar esta concesión. Por supuesto, esta división del trabajo -entre élites y militares políticos- tiene una larga historia en América Latina.

Como estos ejemplos sugieren, los políticos a veces alcanzan bastante autonomía de sus supuestos amos, e incluso los perjudican. En México, la alianza tácita del Partido Revolucionario Institucional-burguesía rompió con las políticas de los presidentes Echeverría y López Portillo (I970-1982), lo que presagió la caída del régimen en 2000. Las 'clases dominantes' del Cono Sur que dieron la bienvenida a los militares tuvieron que repensar esta relación, mientras que en Nicaragua, Cuba y República Dominicana, esas clases lamentaron los excesos de dictadores personalistas como los Somoza, Batista y Trujillo e incluso participaron en los amplios movimientos de oposición contra ellos.

El Estado, entonces, muchas veces dejó de funcionar como el fiel comité ejecutivo de la clase dominante, ya que adquirió su propio poder autónomo. Pero la 'autonomía relativa del Estado' tuvo formas diferentes. Mencionaré cuatro.

Primero, el Estado pudo avanzar en el interés nacional e incluso en su expansión: lo que se puede llamar 'la autonomía prusiana', siendo

${ }^{4}$ Sobre el debate entre Miliband y Poulantzas -a veces (¿mal?) concebido como una disputa entre el 'instrumentalismo' y el 'estructuralismo', véase Clarke (I977: I-3I). 
Prusia -conforme el dicho- no un Estado que tuvo un ejército, sino un ejército que tuvo un Estado (Knight 200I: 182-3). En Europa se ha enfatizado la conexión entre la formación del Estado y la guerra: "los Estados hacen las guerras y las guerras hacen los Estados", en palabras de Charles Tilly (1975: 42). La relación se ve menos claramente en América Latina, donde, no obstante los muchos conflictos bélicos pos-Independencia, la mayoría de las guerras han sido civiles, y las guerras 'totales' -al estilo de las dos guerras mundiales- han sido muy pocas (Centeno 2002). Sin embargo, las guerras (no-civiles) jugaron un papel en la formación del Estado decimonónico en Chile (la Guerra del Pacífico) y Brasil (la Guerra de la Triple Alianza), y dejaron la herencia de fuezas militares fuertes, con prestigio y pretensiones políticas.

Si cambiamos el enfoque hacia adentro, a la relación entre el Estado y la sociedad civil, vemos -esquemáticamente- tres formas de autonomía relativa. Primero, hay formas positivas, que promueven la estabilidad política y/o el desarrollo económico ('positivas' no involucra un juicio de valor: quiere decir simplemente que ayuda a promover la estabilidad y/o el desarrollo, sin aprobar estas metas). Los Estados pueden legitimizarse a sí mismos y al sistema socio-económico, fomentando la educación, la cultura nacional y el consenso (por ejemplo, arbitrando las disputas sociales). De hecho, una tendencia clave en la historia del Estado latinoamericano en el siglo XX fue su mayor penetración social, como educador, benefactor y árbitro. El Estado mexicano -el 'ogro filantrópico'- fue quizás el caso ejemplar; sin embargo, el arbitraje industrial y la reforma laboral se vieron en muchos países como respuesta a la llamada 'cuestión social' de principios del siglo (por contraste, la reforma agraria, elemento clave del proyecto mexicano, tuvo que esperar hasta los cincuenta y sesenta y aún entonces tuvo poco impacto en, por ejemplo, Brasil y Argentina). Los Estados han promovido la cultura, tanto la 'alta' cultura (música, museos, sitios arqueológicos) como la 'baja' (el deporte, especialmente el fútbol), utilizando los nuevos medios masivos: cine, radio y televisión ${ }^{5}$ (pero vale recordar que los actores no-estatales $-\mathrm{y}$ a veces antiestatales, como la Iglesia y el sector privado- se han aprovechado de los mismos medios, a veces con más tino). No quiero negar elementos

${ }^{5}$ Williams (200I) nos da un buen ejemplo. 
idealistas o desinteresados en estas políticas, pero al mismo tiempo tuvieron el objetivo de legitimar tanto al Estado como al orden social. Las respuestas de las clases dominantes fueron diversas: algunas apoyaron estas iniciativas, a veces con miras simplemente instrumentales y preventativas. Como dijo Antonio Carlos de Andrada en Brasil: "nosotros hacemos la revolución antes de que la haga el pueblo" (Weffort I980: I5); pero otras resistieron, a veces exagerando el impacto de reformas moderadas y apoyando una contrarreforma coercitiva, por medio del ejército o de la intervención norteamericana (Guatemala en I954, la República Dominicana en I965, Nicaragua después de 1979).

El Estado también asume un papel autónomo económico, promoviendo la inversión, las obras públicas, la regulación del mercado y la intervención 'keynesiana' para contrarrestar la recesión -acciones que las élites económicas o no quieren o no pueden llevar a cabo. El Estado, pues, suministra las 'externalidades' necesarias. Concretamente, el Estado construyó o subvencionó los ferrocarriles, estableció bancos de fomento (Nacional Financiera, Corporación de Fomento de la Producción) e inyectó liquidez en la economía; por ejemplo, en los años treinta. Cuando la intervención económica estatal fue bien ejecutada, el crecimiento se vio fortalecido, beneficiando a las élites económicas. No obstante, estas solían quejarse del dirigismo y hasta del comunismo del gobierno, tal como hicieron los empresarios de Monterrey contra Cárdenas, haciendo eco de sus colegas norteamericanos en su conflicto con Franklin Roosevelt (Saragoza I988: Cap. 8).

Estos casos están vinculados a la autonomía estatal ejercida con miras y consecuencias positivas. Pero hay otros casos donde la autonomía sirve intereses particulares y personales. Quejas contra la corrupción y los 'busca-rentas' han sido frecuentes: contra el PRI, contra los cleptócratas de la región circun-Caribe y contra elementos militares en el Cono Sur. A veces el Estado fue capturado por intereses regionales: los Tachirenses Castro y Gómez en Venezuela; los Oaxaqueños Juárez y Díaz y los Sonorenses de los años veinte en México; y la alianza 'café con leche’ de São Paulo y Minas Gerais en la vieja república brasileña. Los ejemplos más extremos, ya mencionados, fueron los regímenes personalistas y 'sultanistas' de Trujillo, Somoza y Batista, que saquearon el tesoro y distorsionaron el desarrollo de sus países, desplazando a las 
élites tradicionales (Chehabi y Linz I998). No es sorprendente que las mayores revoluciones del siglo XX fueran dirigidas contra regímenes de esta índole, donde el Estado tajantamente sirvió intereses personales en vez del bien común.

Una conclusión obvia es que es erróneo calificar la intervención -es decir, la autonomía- estatal como necesariamente positiva o negativa; los Estados, como los seres humanos, pueden ser héroes o villanos; y abogar dogmáticamente en pro de políticas dirigistas, por un lado, o de proyectos neoliberales, laissez-faire, por el otro, no ayuda; mucho depende del contexto y, sobre todo, de la naturaleza del Estado que será abultado o adelgazado. Fortalecer un Estado corrupto y autoritario no tiene sentido, como tampoco adelgazar uno capaz, honesto y dotado de visión.

\section{La periodización}

Ahora propongo cuatro períodos en la evolución del Estado latinoamericano: (i) el período pos-independencia: I820 - I860-I870 (40/50 años); (ii) el período de integración global, del llamado 'desarrollo hacia afuera', también mal llamado era 'Liberal': I860 - I870-1930 (60/70 años); (iii) el período de los shocks externos, de introversión económica y de 'desarrollo hacia adentro', también mal llamado era del 'populismo': I930I980 (50 años); y (iv) las recientes décadas del neoliberalismo, de apertura económica, privatización económica y -¿por causalidad necesaria o por mera casualidad?- la democratización del Estado. Esta periodización (enfatizada por Ian Roxborough (I984: I-26) y, más recientemente, por Colin Lewis (2009: I3I-I7I), y que podemos llamar la versión oficial de la London School of Economics), es básicamente económica, y su uso implica una medida de determinismo económico.

\section{I $1820-1860-1870$}

Hay un consenso -correcto- de que los Estados latinoamericanos del primer período fueron débiles. Ahora bien, débiles comparados con qué. Con un puñado de países en Europa (Gran Bretaña, Francia, Rusia) y, más importante, con lo que los Estados latinoamericanos se volverían en el futuro. Su debilidad se ve en una inestabilidad política crónica, la 
falta de 'penetración social' del Estado, su pobreza y su dependencia de instituciones heredadas de la Colonia, como el ejército (tanto el ejército regular como lo que Rouquié (1987) llama los ejércitos 'sociales', encabezados por caudillos populares como Artigas o Páez). La inestabilidad derivó de dos factores, productos de la caída del imperio: la falta de ingresos y la falta de legitimidad. México fue el caso extremo de un síndrome donde el Estado careció de recursos: la minería se desplomó, el comercio exterior, la fuente principal de ingresos, se estancó, y los préstamos extranjeros se agotaron (Tenenbaum I986). Las guerras recurrentes -tanto civiles como internacionales- agotaron el tesoro, no sólo en México sino también en el Río de la Plata y otros países; y la bancarrota motivó más violencia, conforme las tropas se amotinaron o las potencias extranjeras intervinieron para cobrar sus deudas.

Los flamantes Estados también carecieron de la legitimidad que había sostenido a la Corona, al menos hasta fines del siglo XVIII. A pesar de que las estructuras económicas coloniales perduraron (menos el control mercantilista externo), en la América Española se introdujo, un nuevo sistema político republicano, constitucional, basado en la soberanía popular, que, al principio, permitió elecciones de amplia participación (masculina). ${ }^{6}$ La independencia -algo descartada como parteaguas por ciertos historiadores- sí fue una revolución política. Pero la forma de los nuevos Estados quedó incierta, tanto con respecto a sus constituciones (¿federal o centralista? ¿Republicana o monárquica? ¿Tolerante de la Iglesia o anticlerical?) como a sus territorios (¿se mantendrían las Federaciones Centro-americanas y de la Gran Colombia? ¿A quién pertenecería Panamá y la Banda Oriental? ¿Cómo coexistirían Haití y la República Dominicana en la isla de Hispaniola? ¿Quedaría Brasil como un solo Estado lusoparlante, o, de la misma forma que la América Española, se fragmentaría en países distintos?).

Los resultados, claro está, fueron diferentes: la inestabilidad -la 'política de la penuria', en palabras de Barbara Tenenbaum- fue más marcada en México y en el otro corazón del imperio y centro minero, Perú y Bolivia; mientras que Brasil y Chile, con un nivel de exportaciones más alto, fueron más estables, igual que Venezuela y Ecuador. Chile, siendo

\footnotetext{
${ }^{6}$ Eduardo Posada-Carbó (I996) es un buen ejemplo de la 'nueva historia política' del siglo XIX en América Latina, que demuestra la precocidad de la política competitiva electoral en ese siglo.
} 
más homogéneo y centralizado; ganó guerras contra sus vecinos. El éxito (relativo) de los Estados parece depender de dos factores principales: (i) una economía más vigorosa, especialmente en cuanto a las exportaciones se refiere; y (ii) una mayor legitimidad (difícil de medir, es cierto). La legitimidad parece involucrar cierta continuidad neo-colonial: en varios países, los experimentos liberales y federalistas decepcionaron y, hasta los I830 y i840, una reacción conservadora cobró fuerza. En Perú y Bolivia se reintrodujeron los viejos impuestos coloniales (incluso la capitalización); en México y Colombia se restringió el sufragio amplio de la década de i820; en Brasil, la monarquía Braganza garantizó una medida de continuidad, al tiempo que en Chile, Portales -citando 'el peso de la noche' - creó "una fusión del autoritarismo colonial con las formas exteriores del constitucionalismo republicano” (Collier y Sater I996: 54).

\section{$2.21860-1870-1930$}

De ese modo, los fracasos iniciales provocaron una reacción conservadora. Pero en el último tercio del siglo hubo un nuevo giro, mal llamado 'liberal'. Es cierto que los gobiernos ostentaron esta etiqueta, pero es algo engañosa. El secreto del éxito 'liberal' fue convertir el círculo vicioso del estancamiento económico, de la anemia fiscal y de la inestabilidad política en un círculo virtuoso de crecimiento económico (especialmente de exportaciones), solvencia fiscal y establidad política. Como todo 'círculo' de esta índole, fue un proceso de retroalimentación y es difícil decir si el crecimiento económico o la estabilidad política fue lo primordial. Por un lado, el contexto global empujó las exportaciones y la importación del capital; pero, a su vez, el proceso necesitó regímenes 'colaboradores' (con el capital extranjero) para garantizar la inversión, la propiedad y la disciplina social.

Ahora bien, con mayores ingresos y mejor control territorial, los Estados se aproximaron más al ideal weberiano. Su etiqueta 'liberal' fue impugnada por prácticas netamente iliberales: coerción de la mano de obra (peonaje, mandamiento); gobierno autoritario; represión por ejércitos y policías mejor provistos y pagados; tarifas altas (de ahí los crecientes ingresos gubernamentales); y la intervención amplia del Estado en 
la economía -con subvenciones ferrocarrileras, obras públicas (puertos, telégrafos), y esfuerzos para contar la población, reglamentar la propiedad, atraer la inversión y la inmigración extranjera, trazar el territorio nacional y asegurar sus fronteras. Medidas fuertes -iliberales- fueron justificadas por los beneficios futuros (una justificación que se remonta a Portales): los 'flojos nativos' requerían disciplina y la propiedad corporativa debió ser desamortizada para liberar la mano mágica del mercado. Como suele pasar, las medidas temporales e instrumentales se volvieron duraderas porque favorecieron intereses poderosos.

El iliberalismo de la era liberal se ve más claramente en la 'Indo-América' (México y los países andinos y centroamericanos), donde Estados fuertes y autoritarios se dedicaron al desarrollo económico y a la represión social: Díaz en México, Estrada Cabrera en Guatemala, Leguía en Perú. En el Cono Sur, el liberalismo fue menos hipócrita: el desarrollo hacia afuera, muy dinámico y llevado a cabo por regímenes civiles y oligárquicos, no dependió de la coerción de la mano de obra, ni de la expropiación de densas comunidades campesinas; la mano de obra vino de Europa, atraída por mejores sueldos y condiciones (en Chile, en tanto, los terratenientes encontraron una amplia fuente de trabajo en sus inquilinos). Por tanto, regímenes genuinamente liberales crecieron en el Cono Sur y posibilitaron una transición hacia la democracia (limitada) con Batlle en Uruguay e Yrigoyen en Argentina. Una bifurcación algo parecida occurrió en Centroamérica, donde la producción y exportación de café fomentaron un autoritarismo racista (pero nominalmente 'liberal') en Guatemala y El Salvador, pero un régimen más civil, oligárqico y plural en Costa Rica; una bifurcación que tendría resultados de larga duración en el siglo XX.

Es decir, las consecuencias políticas del desarrollo económico exportador fueron distintas. Hubo por todos lados un crecimiento del poder del Estado, gracias a la tecnología y los ingresos. Todo Estado intervino sistemáticamente en la economía, pero la coerción de la mano de obra -aunada a doctrinas positivistas y racistas- fue variable. En ciertos Estados, como mencioné, hubo una división del trabajo, conforme los políticos especialistas -caciques y caudillos, coroneles y gamonalesejercieron el poder, especialmente en las localidades, mientras que los 'oligarcas' controlaron la riqueza nacional (generalmente en colabora- 
ción con el capital extranjero); a veces ocuparon las cúpulas políticas (Ejecutivo y Legislativo) y, en el caso de los millonarios argentinos, pasaron el invierno en la Riviera francesa. El Estado 'liberal' u 'oligárquico' de ese entonces no fue un agente sencillo de las élites económicas, pero protegió sus intereses, ya sea debido a la presencia oligárquica en el gobierno o a la división del trabajo político. A esto se le agregó el hecho de que las exportaciones pagaron los gastos del Estado.

\section{$2.31930-1980$}

Este círculo virtuoso -a ojos del Estado, de las élites y de sus aliados extranjeros- se derrumbó en gran parte debido a los tres grandes shocks externos (aunados a las presiones internas): las dos Guerras Mundiales y la Gran Depresión. No obstante las diferencias nacionales, hubo patrones comunes. Las exportaciones declinaron, fomentando una actitud de 'pesimismo exportador', un cambio de énfasis hacia el mercado doméstico y cierta disposión hacia políticas heterodoxas, incluso keynesianas (o 'proto-keynesianas'). Lógicamente, estas tendencias fueron más marcadas en las economías mayores (México, Brasil, Chile, Argentina), donde el mercado interno era más profundo y la Industrialización por Sustitución de Importaciones (ISI) más viable; todo lo cual benefició a los industriales $-\mathrm{y}$, en cierta medida, a los obreros industriales- $\mathrm{y}$ a ciudades como Monterrey, São Paulo y varias capitales (Ciudad de México, Santiago, Buenos Aires). El proceso de ISI también aumentó el papel del Estado, evidente en el crecimiento del gasto público entre I930 y I970 (especialmente en Brasil y Chile). Aun cuando la ISI no se implementó en algunos casos -como en Cuba- el Estado (lo que Domínguez 1978: Cap. 3, llama 'el Estado regulador') asumió un papel central en la producción y la exportación azucarera. En Perú y Ecuador, el balance entre las élites serranas y costeñas se inclinó hacia estas últimas. Y en todos los países los sindicatos cobraron fuerza y el movimiento obrero se volvió el objeto, ya no tanto de la represión estatal (como en Cananea e Iquique en I907), sino de la regulación y la cooptación oficial. 
Los patrones económicos comunes no quieren decir que las consecuencias políticas fueron iguales; cuesta trabajo ver un Estado típico (por ejemplo, 'populista'), producto de este período. Primero, el populismo floreció en países donde la ISI fue escasa o ausente: en la Cuba de Batista y la Nicaragua de Somoza (me refiero a los años cuarenta), con Odría en Perú y con el Velasquismo en Ecuador (Knight I998: 237-8). Por contraste, Colombia y Chile experimentaron la ISI sin volverse semilleros de populismo. La incorporación política de los obreros organizados, enfatizada por Berins Collier y Collier (1992), pudo asumir formas populistas (por ejemplo en Argentina) y no-populistas (como en Chile). La divergencia se debe a que el populismo es un fenómeno político, resultado de sistemas políticos particulares; suele florecer donde los partidos son débiles, cuando líderes 'carismáticos' se granjean el apoyo popular fuera de éstos, y cuando las crisis provocan la movilización política (y clasista) y propician la polarización entre 'ellos' y 'nosotros'. Tales circunstancias han provocado brotes populistas, tanto en América Latina como en Europa y Estados Unidos, incluso antes y después del tercer período (supuestamente 'populista'). De ahí los 'proto-populistas', como Yrigoyen, y los 'neo-populistas' como Menem y Fujimori. Ademas, en pleno período 'populista', la mayoría de los políticos no mostraron rasgos populistas.

Por tanto, aunque 'populista' puede ser una etiqueta algo útil, que indica un estilo particular, no puede servir como etiqueta para todo un período político. Es igual con el enemigo hereditario del populismo, es decir, el pretorianismo (el militarismo político o, si seguimos a O’Donne11 (I996), el 'autoritarismo burocrático'),7 otro rasgo de este período. Por supuesto, la intervención militar ha tenido una larga historia en América Latina. Lo nuevo, en este período, fue la intervención no de caudillos 'tradicionales' (Páez, Artigas, Santa Anna) sino de ejércitos modernos, comprometidos con un ambicioso proyecto de renovación político-económica. Por ello, sus intervenciones fueron más duras y duraderas.

O’Donnell enfatizó -y exageró- la lógica econonómico-industrial de este fenómeno (la función del autoritarismo burocrático fue profundizar la ISI en su etapa 'dificil'). Pero hubo otros factores económicos en 
juego (la inflación y las crisis de la balanza de pagos); y factores políticos, dos de los cuales vale subrayar. Este tercer período fue testigo de grandes confictos internacionales, que culminaron en la Guerra Fría, cuya lógica maniquea fomentó la polarización política y motivó mayor intervención por parte de los Estados Unidos (mucho mayor que la intervención británica en el siglo XIX). Conforme cobró fuerza el intervencionismo norteamericano -tanto militar como pacífico- los políticos latinoamericanos aprendieron a manipular este factor para su ventaja (en esto sobresalieron los brasileños). Claro, el poder estadounidense fue limitado (por tanto la Revolución Cubana sobrevivió), pero fue suficiente para apuntalar regímenes predilectos (Batista, Somoza), moldear otros (como el Movimiento Nacionalista Revolucionario (MNR) en Bolivia) y debilitar otros (Goulart, Allende, los Sandinistas), contribuyendo así a la polarización política de la época.

Pero la polarización de la Guerra Fría también tuvo raíces domésticas, ${ }^{8}$ relacionadas con el cambiante balance entre élites industriales y agrarias, el auge sindical, el crecimiento de partidos masivos (MNR, Acción Democrática, Alianza Popular Revolucionaria Americana), y la expansión del Estado -en términos de gasto y regulación. Lo anterior fomentó una contienda más feroz para controlar el nuevo Leviatán, una entidad que se introdujo cada vez más en la vida social y económica, por medio de tarifas, cuotas, leyes laborales, escuelas, universidades, impuestos, políticas culturales y, por fin, las reformas agrarias. De hecho, estas parecen mostrar cierta correlación con los golpes militares, especialmente en Brasil (1964) y Chile (1973). Por contraste, la notable estabilidad civil de México en este período se debe en parte a su precoz reforma agraria de los años veinte y treinta. Cuando se trata de trayectorias nacionales y crisis socio-políticas, la incorporación campesina puede ser no menos importante que la obrera, enfatizada por Berins Collier y Collier (I992).

8 La manera en que la Guerra Fría afectó y agudizó los antiguos conflictos políticos, fomentando una mayor polarización se ve muy claramente en la Violencia Colombiana, cuando Laureano Gómez -líder y presidente conservador- tildó a sus contrincantes liberales de ser "comunistas y cripto-comunistas" (Pécaut I987 T.II: 53I-3). 


\section{$2.41980-2012$}

Por último, llegamos al período actual del neo-iberalismo y del debilitamiento del Estado, en cierto sentido un cambio de dirección en ciento ochenta grados. Otra vez, no obstante las muchas variaciones, hubo un patrón común: apertura económica, acuerdos comerciales, mayor participación en la economía mundial y recortes en el gasto público. El Estado repudió (en parte) el nacionalismo económico, la protección y el dirigismo, lo que conllevó una disminución en su capacidad para 'premiar a sus amigos y castigar a sus enemigos' por medio de puestos, privilegios, subsidios y sobornos. El proceso fue parcial: Brasil ha mantenido un sector estatal fuerte; en México, Pétroleos Mexicanos (PEMEX) continúa siendo la vaca lechera del gobierno (durante doce años un gobierno del Partido Acción Nacional); mientras que el Chavismo ha dependido de los ingresos petroleros para sus políticas domésticas y extranjeras. Además, si la nacionalización de REPSOL por el gobierno argentino es un botón de muestra significante (y no un mero capricho de la Presidenta), quizás el ciclo de liberalización y privatización se está terminando, al menos en los países donde la llamada izquierda 'populista' tiene el poder (Argentina, Venezuela, Bolivia, Ecuador). En otras partes (de mayor peso económico) la izquierda socialdemócrata parece haber establecido cierto balance entre el mercado libre (y la confianza internacional), por un lado, y el papel redistributivo del Estado, por otro. Las administraciones de Lula y Bachelet son un buen ejemplo de ello. ${ }^{9}$

El último aspecto obvio de este período ha sido la restauración de la democracia, parte 'de la tercera ola' que, de acuerdo con Samuel Huntington (I991: 2I-6), comenzó en la década de ı970. Otra vez, Cuba es una excepción (¿y quizás Honduras?); y hay quienes cuestionan el carácter de la democracia en los países del populismo izquierdista ya mencionados. Sin embargo, conforme a los criterios de Dahl (I97I), América Latina hoy en día es más democrática que nunca y la evidencia sugiere una continuación de gobiernos democráticos, no su derrumbe (¿quién los derrumbaría?: ni la izquierda revolucionaria ni los militares tienen ganas -o capacidad; mientras que los Estados Unidos, metidos en intervenciones en otras partes, han dejado de intervenir en el sur). Por 
supuesto, las democracias actuales son 'de baja intensidad', donde el Estado de derecho es débil (México, Brasil, Colombia); y, en la medida en que han emulado las virtudes de la democracia contemporánea en Europa o Estados Unidos, han adquirido los defectos de estas virtudes: un achicamiento del abanico de opiniones y proyectos; un papel clave para la empresa privada y el cabildeo; y campañas políticas dominadas por la televisión, los spots y candidatos seleccionados por sus méritos telegénicos y sus bolsillos profundos. 'Dénme un balcón y les daré el país', dijo Velasco Ibarra (supuestamente); hoy en día, debería cambiar su balcón por una serie de spots televisivos. Cuesta trabajo imaginar a los grandes estadistas del pasado -Irigoyen, Alessandri, Cárdenas, Vargas, Haya de la Torre- forjando sus carreras en estas circunstancias.

Para concluir: ¿cuál fue el impacto del neoliberalismo sobre el Estado? Dos puntos valen ser mencionados. El adelgazamiento del Estado puede disminuir su poder (material, redistributivo, clientelístico), pero no necesariamente cuestiona la legitimidad del régimen o del Estado. Un Estado más delgado (pequeño -pero eficiente, honesto y cumplidor) bien puede que sea más legítimo que un Estado 'obeso' pero corrupto e ineficaz, como sugiere la historia de México en la segunda mitad del siglo veinte. Quizás también la historia contemporánea de Grecia. Claro, un Estado poderoso -como en Escandinavia- también puede gozar de alta legitimidad. Todo depende de la naturaleza del Estado: presumo que prefirimos que nuestros héroes sean fuertes, y nuestros villanos enjutos.

Segundo punto: se ha dicho que el neoliberalismo económico y la democracia política están relacionados causal y funcionalmente. Puede ser que a veces esto sea cierto, pero no es una ley fija. Entre las democracias más estables están las de Escandinavia, que tienen sectores estatales grandes, basados en impuestos altos y políticas de redistribución; es decir, aunque son básicamente capitalistas, no se acercan al modelo neoliberal (o 'anglosajón'). Eso no quiere decir que el modelo escandinavo sea fácilmente exportable; y la historia de la importación de modelos por América Latina -que ha pasado por una serie de modelos preferidos- no es muy prometedora. La restauración de la democracia durante y después de la crisis de la deuda fue en parte una coincidencia feliz (feliz si uno piensa que la democracia es preferible). La crisis intervino cuando proliferaron gobiernos autoritarios, que tuvieron que soportar el impacto 
(como hicieron los gobiernos civiles y democráticos en los años treinta); por tanto, los regímenes militares del Cono Sur cayeron, mientras que la 'dictadura perfecta' del PRI comenzó a desmoronarse. La democracia fortuita quizás no es la base más fuerte para la consolidación democrática; y, por supuesto, han existido olas de democratización y autoritarismo en el pasado. Sería riegoso asumir, con Fukuyama (i992), que la democracia es 'el único juego en el pueblo'. Si eso es cierto, al menos para el futuro previsible (que, como historiador, calculo como en diez minutos) puede ser que esto tenga menos que ver con la relación democracia/ liberalismo económico que con la evolución de larga duración de los Estados y regímenes latinoamericanos. Quizás, después de dos siglos de dura experiencia, los latinoamericanos han llegado a la misma conclusión que Winston Churchill hace cincuenta años: que la democracia es la peor forma de gobierno, salvo todas las demás que han sido probadas. 
BIBLIOGRAFÍA

Berins Collier, R., y Collier, D. I992. Shaping the Political Arena. New Jersey: Princeton University Press.

Brading, D.A. I99I. The First America: The Spanish Monarchy, Creole Patriots and the Liberal State, 1492-1867. Cambridge: Cambridge University Press.

Centeno, M.A. 2002. Blood and Debt: War and the Nation-State in Latin America. Pennsylvania: University Park.

Chehabi, H.E., y Linz, J. I998. Sultanistic Regimes. Baltimore: Johns Hopkins University Press.

Clarke, S. I977. Marxism, Sociology and Poulantzas' Theory of the State. Capital and Class, I(2), I-3I.

Collier, D. I979. The New Authoritarianism in Latin America. New Jersey: Princeton University Press.

Collier, S. 1967. Ideas and Politics of Chilean Independence, 1808-1833. Cambridge: Cambridge University Press.

Collier, S. y Sater, W. I996. A History of Chile, 1808-1994. Cambridge: Cambridge University Press.

Dahl, R.A. I97I. Polyarchy: Participation and Opposition. New Haven: Yale University Press.

Domínguez, J.I. I978. Cuba: Order and Revolution. Cambridge: Harvard University Press.

Evans, P.B., Rueschmeyer, D., Skocpol, T. I985. Bringing the State Back In. Cambridge: Cambridge University Press.

Fukuyama, F. 1992. The End of History and the Last Man. New York: Simon \& Schuster.

Gamio, M. I9I6. Forjando Patria: Pro-Nacionalismo. Boulder: University Press of Colorado.

Gellner, E. I983. Nations and Nationalism. Ithaca: Cornell University Press.

Hobsbawm, E. I992. Nations and Nationalism Since 1780. Cambridge: Cambridge University Press.

Hora, R. 200I. Landowners of the Argentine Pampas: A Social and Political History, 1860-1945. Oxford: Oxford University Press. 
Hume, D. 1739. Treatise of Human Nature. Oxford: Clarendon Press.

Hume, D. [I74I-2]. I963. Essays Moral, Political and Literary. Oxford: Oxford University Press.

Huntington, S.P. I99I. The Third Wave. Democratization in the Late Twentieth Century. Norman: University of Oklahoma Press.

Knight, A. I998. Populism and Neo-populism in Latin America, Especially Mexico. Journal of Latin American Studies 30, 223-248.

Knight, A. 200I. The Modern Mexican State: Theory and Practice. En M.A. Centeno y F. López-Alves, The Other Mirror: Grand Theory through the Lens of Latin America. Princeton: Princeton University Press.

Landes, D. I998. The Wealth and Poverty of Nations. London: W.W. Norton \& Co.

Lewis, C. 2009. The State and Economic Growth in Latin America. En R. Stemplowski (ed), On the State of Latin America States. Krakow: Polski Instytut Spraw Miedzynarodowich.

Miliband, R. I973. The State in Capitalist Society. London: London Quartet Books.

O’Donnell, G. I996. El Estado burocrático-autoritario. Buenos Aires: Editorial Belgrano.

Pécaut, D. I987. Orden Y violencia: Colombia, 1930-54. Bogotá: CEREC.

Peña Nieto, E. 20I2. Mexico: The Great Hope. México: Edamsa.

Posada-Carbó, E. (ed) I996. Elections Before Democracy: The History of Elections in Europe and Latin America. Nueva York: St. Martin`s Press.

Rock, D. I987. Argentina, 1516-1987. Berkeley: University of California Press.

Rouquié, A. I987. The Military and the State in Latin America. Berkeley: University of California Press.

Roxborough, I. I984. Unity and Diversity in Latin American History. Journal of Latin American Studies I6(I), I-26.

Rutledge, I. I977. The Integration of the Highland Peasantry into the Sugar Cane Economy of Northern Argentina, I930-43. En Duncan, K. y Rutledge, I. (eds), Land and Labour in Latin America. Cambridge Latin American Studies 26, 205-228.

Saragoza, A. 1988. The Monterrey Elite and the Mexican State, 1880-1940. Austin: University of Texas Press.

Scott, J.C. I990. Domination and the Arts of Resistance. New Haven: Yale University Press.

Stepan, A.C. I978. The State and Society: Peru in Comparative Perspective. New Jersey: Princeton University Press. 
Tenenbaum, B. 1986. The Politics of Penury. Debts and Taxes in Mexico, 1821-1856. Albuquerque: University of New Mexico Press.

Tilly, C. I975. The Formation of National States in Western Europe. New Jersey: Princeton University Press.

Véliz, C. I980. The Centralist Tradition of Latin America. New Jersey: Princeton University Press.

Weber, M. I964. The Theory of Social and Economic Organization. New York: The Free Press.

Weffort, F.C. I980. O populismo na politica brasileira. Rio de Janeiro: Paz e Terra.

Williams, D. 200I. Culture Wars in Brazil: The First Vargas Regime, 1930-45. Durham: Duke University Press.

Woodard, C. 20II. American Nations: A History of the Eleven Regional Cultures of North America. New York: Penguin Group.

Recibido septiembre 2013

Aceptado enero 20I4 